\title{
STABILITY OF DOUBLE-WALLED MANGANIN RESISTORS
}

\author{
By James L. Thomas
}

\section{ABSTRAC'T}

The international ohm is now maintained at the National Bureau of Standards by means of double-walled manganin resistors. It is assumed that the average resistance of a group of 10 standards, selected from a group of 24 constructed in 1933, remains constant with time. No one of the 10 standards has changed in resistance with reference to their average by more than 1 part in a million in 12 years.

I. Introduction 107

II. Description of new resistors

III. Stability of resistance. 109

\section{INTRODUCTION}

Although the international ohm is defined in terms of the resistance of a column of mercury, wire-wound standards are used at national standardizing laboratories for maintenance of the unit of resistance. At the National Bureau of Standards the international ohm is maintained by means of a group of 1-ohm resistors. From this group 10 standards have been selected, and the assumption is made that the average of their resistances remains constant with time. If there is a relatively large change in the resistance of one standard with reference to the average, it is replaced with one that has remained constant. In this way standards are eliminated from the reference group when they become defective.

Values of resistance were originally assigned to standards of the reference group in terms of mercury-ohm determinations made in England and in Germany before 1910. Mercury-ohm determinations were made at this Bureau in 1911 and 1912, and the results were consistent with the English and German results to 15 or 20 parts in a million. ${ }^{1}$ In 1910 the reference group consisted of 1-ohm standards of the type developed by Rosa, ${ }^{2}$ and resistors of that group were used for over 25 years. Starting in 1931 the standards of the Rosa type were gradually replaced by standards of the double-walled type. ${ }^{3}$ Since 1939, maintenance of the international ohm has been entirely by means of a new group of double-walled resistors constructed in 1933. Resistors of the later group have been far superior to any others made at this Bureau, and, judged on the basis of relative stability, are about one order better than well-aged standards of the Rosa type. It is the purpose of this paper to describe the new standards and give a report of their performance to date.

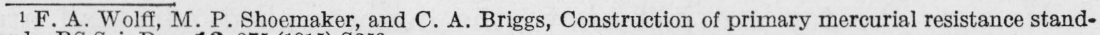
ards, BS Sci. Pap. 12, 375 (1915) S256.

2 E. B. Rosa, A new form of standard resistance, BS Sci. Pap. 5, 413 (1908-9) S107.

3 J. L. Thomas, A new design of precision resistance standard, BS J. Research 5, 295 (1930) RP201.
} 


\section{DESCRIPTION OF NEW RESISTORS}

The standards constructed in 1933 consisted of a group of 24 of the double-walled type, and the same technic was used for annealing and mounting as that described in Research Paper RP201. The containers, however, were larger than those of the original double-walled group, and were similar in size and general appearance to O. Wolff's model IV.

The increase in the size of the containers made possible the use of larger resistance wire, thus decreasing the ratio of area to volume and thereby reducing possible changes in resistance from surface changes. The resistance coils were made of 28 turns of No. 12 AWG manganin wire $\left(2.05 \mathrm{~mm}=0.081\right.$ in.) from two lots of specially selected wire, ${ }^{4}$ wound on 8-cm mandrils and spaced with copper wire. Before the wire was annealed, it had a slightly negative temperature coefficient of resistance at $25^{\circ} \mathrm{C}$, and after being annealed, the coefficients were very small, averaging 1 part in a million per degree centigrade for the 24 standards, the maximum coefficient being $3.05 \mathrm{ppm}$ per degree centigrade.

For annealing the resistance coils, a special furnace was constructed, using a fuzed-quartz tube about $10 \mathrm{~cm}$ in diameter and $75 \mathrm{~cm}$ in length. This tube was sealed at one end, and the other end was covered with a ground-glass plate through which were sealed thermocouple leads and an exhaust tube. Several parallel aluminum plates were placed in front of the glass cover plate to protect it from radiant heat from inside the furnace. The heating coil around the tube was nowhere nearer than 6 inches to the cover plate, and a good seal was maintained by the use of ordinary stopcock grease.

The resistance coils mounted on the steel mandrils were annealed in the quartz furnace. An oil-sealed pump was used to evacuate the furnace, maintaining a pressure of the order of $0.001 \mathrm{~mm}$ of mercury. About an hour was required to bring the furnace to the annealing temperature of $550^{\circ} \mathrm{C}$, at which it was maintained for half an hour, after which the power supply was disconnected and the furnace allowed to cool fairly rapidly.

After the annealed resistance coils had been adjusted to the correct lengths, manganin terminal plates were silver-soldered to the ends. Manganin rather than copper plates were used in order to keep the temperature coefficient of resistance as low as possible.

The mounted resistance coils were spaced with many turns of linen thread wound between the turns of wire. All but two of the coils were then impregnated with shellac varnish and baked at $120^{\circ} \mathrm{C}$ before sealing them in dry air in the containers. In the 2 months immediately after sealing, each resistor, except the two which were not shellacked, decreased in resistance by from 1 to 5 parts in a million, after which the resistance appeared to be stabilized. No change was obtained even during the initial period for the coils that were not shellacked, which suggests that the initial change was from dimensional changes in the shellac.

One of the completed standards is shown in figure 1. The outside diameter of the container is $9 \mathrm{~cm}$ and its length $13 \mathrm{~cm}$. The series of holes near the top are just above the double-walled part and are intended to increase the facilities for cooling, and the containers are

${ }^{4}$ Chemical analysis of one lot: $\mathrm{Cu} 82.2$, Mn 13.2, Ni 4.2, Fe 0.3; of second lot, $\mathrm{Cu} 82.7, \mathrm{Mn} 12.1, \mathrm{Ni} 4.6$, $\mathrm{Fe} 0.5$. 


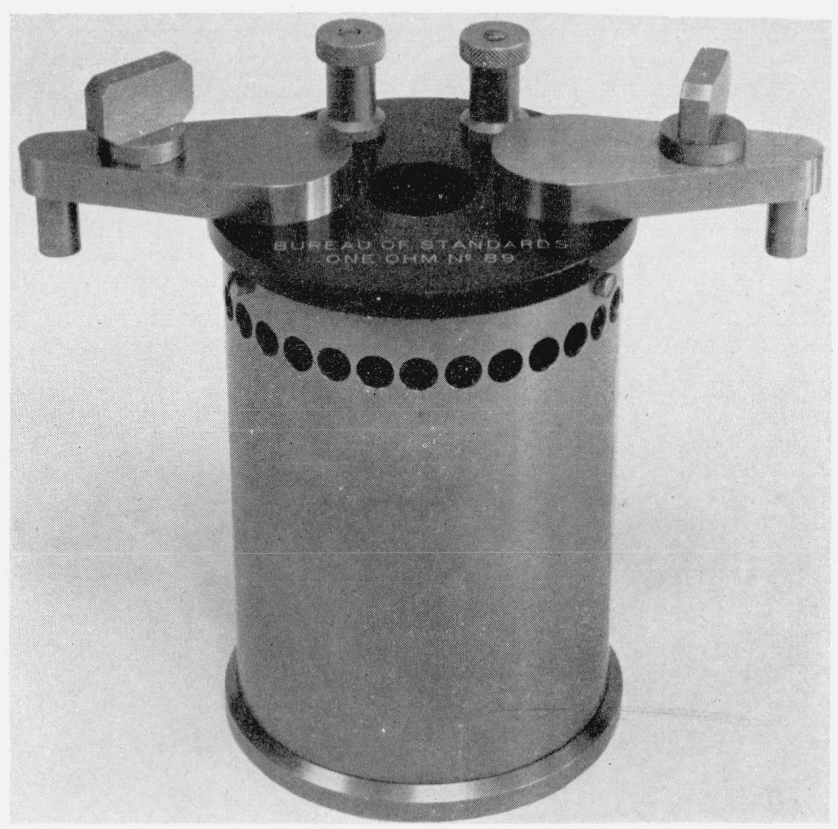

FigURE 1.-Double-walled standard resistor. 
left open at the bottom for the same purpose. The terminal posts are entirely of nickel-plated copper, mounted on a hard-rubber top; the distance between the amalgamated current terminals being $16 \mathrm{~cm}$. it.

\section{STABILITY OF RESISTANCE}

In the fall of 1933, after all standards had been on hand for at least 2 months, the group of 24 was intercompared, resistance measurements being made to parts in 10 million. Three of the standards were then sent to the International Bureau of Weights and Measures, and since that time four more have been sent to other national laboratories. The remaining 17 standards have been intercompared to parts in 10 million nearly every year since their completion. Two of the standards have changed in resistance by 4 and 8 parts in a million, in the 12 years since their construction and are considered to be of inferior quality. The remaining 15 resistors comprise the group now used for maintenance of the international ohm. The average value of 10 standards is assumed to remain constant with time, and 5 are kept in reserve to replace standards in the group of 10 if any of them should become defective and change in resistance by an unusual amount.

TABLE 1.-Stability of double-walled resistors in maintenance group

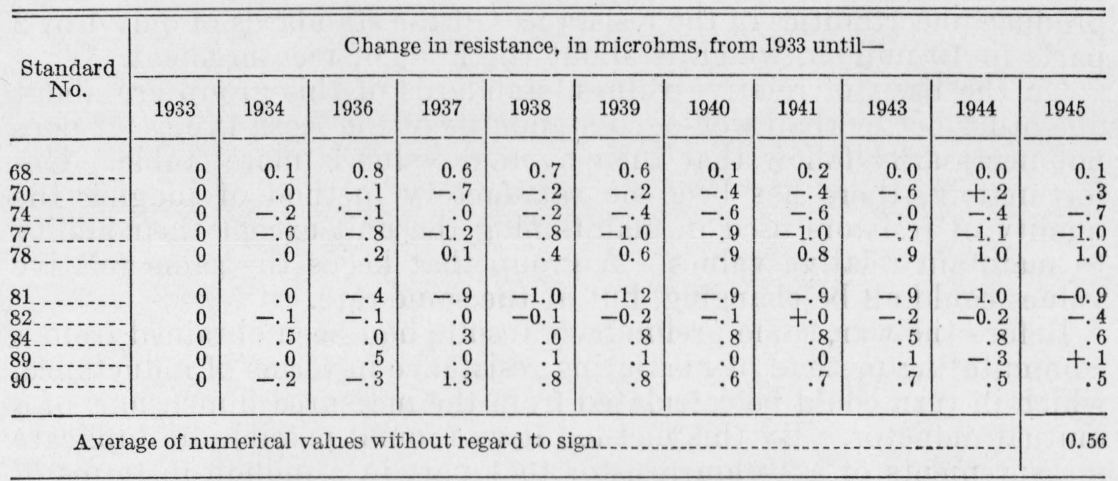

Table 1 shows how exactly standards in the maintenance group of 10 have kept their relative values during the last 12 years. This table shows the total change, in parts per million, since 1933, calculated on the assumption that their average value has remained constant. Table 2 gives similar data for the 5 reserve standards, measured in terms of the average of the group of 10 . Data for the 5 are somewhat incomplete.

TABLE 2.-Stability of double-walled resistors in reserve group

\begin{tabular}{|c|c|c|c|c|c|c|c|c|c|c|c|}
\hline \multirow{2}{*}{$\begin{array}{l}\text { Standard } \\
\text { No. }\end{array}$} & \multicolumn{11}{|c|}{ Change in resistance, in microhms, from 1933 until- } \\
\hline & 1933 & 1934 & 1936 & 1937 & 1938 & 1939 & 1940 & 1941 & 1943 & 1944 & 1945 \\
\hline $\begin{array}{l}67 \\
73 \\
73 \\
83\end{array}$ & $\begin{array}{l}0 \\
0 \\
0 \\
0 \\
0\end{array}$ & $\begin{array}{r}1.1 \\
-0.1 \\
.2 \\
.0 \\
.2\end{array}$ & $\begin{array}{r}0.6 \\
.1 \\
.3 \\
.4\end{array}$ & $\begin{array}{r}-0.1 \\
.1 \\
.0 \\
.2\end{array}$ & $\begin{array}{r}-0.2 \\
.7 \\
-.2\end{array}$ & $\begin{array}{r}-0.4 \\
1.0\end{array}$ & $\begin{array}{r}-0.5 \\
1.2 \\
-2 \\
\end{array}$ & $\begin{array}{r}-0.6 \\
1.5\end{array}$ & $\begin{array}{r}1.9 \\
-1.5\end{array}$ & $\begin{array}{r}-0.9 \\
2.0 \\
0.6 \\
-.8 \\
-1.9\end{array}$ & $\begin{array}{r}-1.5 \\
1.9 \\
0.4 \\
-.9 \\
-2.1\end{array}$ \\
\hline
\end{tabular}


For the 10 resistors now being used in maintaining the international ohm, the maximum net change in 12 years has been 1.0 part per million. The average net change without regard to sign has been 0.56 part per million in 12 years, or at the average yearly rate of about 5 parts in 100 million.

The bridge which has been used for the intercomparison of these resistors has dials that can be set to parts in a million, the next place being obtained from galvanometer deflections. The method of measurement is such that the bridge is relied upon to measure differences in resistance only. The facilities for cooling and the lowtemperature coefficients of resistance make possible measurements to 1 or 2 parts in 10 million, when the standards are measured in a well-stirred, thermostatically controlled, oil bath.

With double-walled containers having the resistance coils mounted tightly in contact with one wall, variations in atmospheric pressure tend to expand or compress the walls and thus apply stresses to the coils. To test the change in resistance so produced, three of the double-walled resistors were placed in a closed chamber and measured at about normal and half-normal pressures. The decrease in resistance as the pressure changed from normal to half-normal was found to be from 2 to 4 parts in a million. Assuming the change to be linear, changes in barometric pressure can therefore be expected to produce uncertainties in the resistances of the standards of only 1 or 2 parts in 10 million, which is about the limit of measurement.

On the basis of relative values, standards of this group are about one order better than well-aged standards of the Rosa type. It does not necessarily follow that their average value is more stable. Unfortunately, there has been no satisfactory method of judging the quality of resistors used in maintaining the unit except their ability to maintain relative values. A group that keeps the same relative values could all be changing, but at the same rate.

Before the war, some preliminary results had been obtained from a commutating method of measuring resistance in terms of inductance, which in turn could be calculated from the measured dimensions of a mutual inductor. By this method it was found possible to duplicate measurements of a 1-ohm resistor to 1 part in a million in terms of the calculated mutual inductance. It is expected that such measurement will in the future give data on the stability of groups of resistors over long periods of time. The stability of the inductor can be checked from time to time from its measured dimensions, and it is believed that this can be done to 1 part in a million. Measurements of the resistors in terms of the inductance would then disclose changes as large as 1 or 2 parts in a million in the resistance of the group being used to maintain the unit. It is not expected that resistance can be measured in absolute units to 1 part in a million by this method. It does appear, however, that systematic errors will be sufficiently constant to permit checks of the stability of the unit of resistance to 1 or 2 parts in a million.

Washington, September 24, 1945. 